\title{
Correlation of primary tumor metabolic parameters with clinical, histopathological and molecular characteristics in breast cancer patients at pre-operative staging FDG-PET/CT study
}

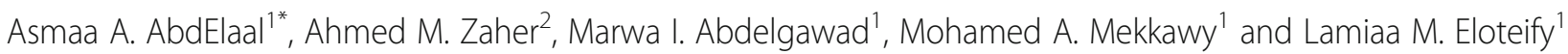

\begin{abstract}
Background: The aim of this prospective study was to evaluate the correlation of primary tumor metabolic activity parameters; maximum standardized uptake value (SUVmax) and tumor SUVmax/liver average SUV ratio (TLR) with clinical, histopathological and molecular characteristics of initial staging breast cancer (BC) patients using 18Ffluorodeoxyglucose (FDG) positron emission tomography / computerized tomography (PET/CT) scan.

Results: Forty female patients with newly diagnosed BC were enrolled in our study, age ranging from 31-78 years (mean $50.5+$ +- SD11.7).

All the primary tumors were detected with mean SUVmax 10.8(+/-SD 7.9). The mean /median SUVmax values of primary tumor was higher in premenopausal, stage III and IV, Estrogen Receptors negative( ER-), Progesterone Receptors negative(PR-), Human epidermal growth factor receptor 2 positive ( Her2neu+) patients, high nuclear grade (GIII), triple negative molecular subgroup (TN) and positive axillary lymph node (ALNs) metastasis, $(P=0.003$, $0.017,0.113,0.0890 .01,0.002,0.007$ and 0.016 respectively).

The mean/median TLR values was higher in premenopausal ,Her2neu+, GIII, TN molecular subtype patients, stage III and IV and in patients with positive ALNs, ER- and PR - patients $(P=0.002,0.0476,0.005,0.018,0.039$ and 0.022 , 0.095 and 0.129 respectively).

SUVmax of the primary lesion and TLR were moderately negatively correlated with the age of the patients $(P=$ 0.005 and 0.008 respectively), also they were moderately positively correlated with the size of the primary tumor $(P=0.019$ and 0.036 respectively). TLR was predictive of nodal involvement $A U C=0.612$ (95\% Cl: $0.431-792)$. The overall sensitivity and specificity of PET/CT for axillary staging was $100 \%$ and $60 \%$, respectively $(P=0.006)$.
\end{abstract}

Conclusion: The SUVmax of the primary tumor and TLR values had similar significant associations with different prognostic factors in BC but only TLR can predict nodal involvement.

Keywords: Breast cancer, Initial staging, FDG PET/CT, SUVmax, TLR

\footnotetext{
* Correspondence: asmaa2011@aun.edu.eg

'Department of Clinical Oncology and Nuclear Medicine, Faculty of

Medicine, Assiut University, Assiut, Egypt

Full list of author information is available at the end of the article
}

\section{Springer Open}

(c) The Author(s). 2021 Open Access This article is licensed under a Creative Commons Attribution 4.0 International License, which permits use, sharing, adaptation, distribution and reproduction in any medium or format, as long as you give appropriate credit to the original author(s) and the source, provide a link to the Creative Commons licence, and indicate if changes were made. The images or other third party material in this article are included in the article's Creative Commons licence, unless indicated otherwise in a credit line to the material. If material is not included in the article's Creative Commons licence and your intended use is not permitted by statutory regulation or exceeds the permitted use, you will need to obtain permission directly from the copyright holder. To view a copy of this licence, visit http://creativecommons.org/licenses/by/4.0/. 


\section{Background}

$\mathrm{BC}$ is the commonest cancer and the leading cause of cancer mortality among women worldwide [1].Classification can be done according to TNM stage, immunohistochemical features, grade, proliferation index and gene expression profiles, with histopathology remaining the cornerstone of characterization [2]. Immunohistochemistry (IHC) markers such as ER, PR and Her2neu, along with clinicopathological variables including; tumor size, grade and nodal involvement are commonly used for patient prognosis and management $[3,4]$. Various imaging modalities are used in the diagnosis of $\mathrm{BC}$ including : ultrasound, mammography and magnetic resonance imaging [5]. Recently, functional imaging with F18-FDG PET/CT is increasingly used [6]. F18-FDG PET/CT is a noninvasive method, based on the principle of elevated glucose metabolism in malignant tumors; it detects distant metastasis as well as providing additional information about tumor histology [7, 8]. In patients with locally advanced BC, 18F-FDG PET/CT can be useful prior to surgery or neoadjuvant chemotherapy as it detects distant metastasis with a high rate $(6 \%$ to 26\%). 18F-FDG PET/CT can change the treatment plane in $1 \%-8 \%$ of patients with early-stage $\mathrm{BC}$, in $7 \%-13 \%$ of those with locally advanced disease and in up to $52 \%$ of those with aggressive tumors [9].

Studies suggested that the quantitative PET parameter in the form of SUVmax is useful for predicting histologic, biologic characteristics of the tumor and patient's prognosis $[8,10]$. Invasive tumors exhibit higher uptake values than lower-grade one [11].Many factors affect the SUVmax value, including the blood glucose level, body weight, duration after injection, size of the region of interest (ROI), and resolution of the scanner. Also it is susceptible to the impact of noise, partial volume effect, image resolution and determination of the volume of interest (VOI )- a single-voxel value representing the most intense FDG uptake in the tumor. These factors delimit the reliability of the absolute value to represent for the glucose metabolic rate of tumors [12, 13].So the SUVmax may not be an adequate measure for the metabolic rate of the tumor. It has been suggested that some of the problems may be eliminated by using TLR [14, 15]. The mediastinal vessels and normal liver tissue are the most commonly used parameters for individual background activity [16] .Using the SUV liver to represent individual normal uptake that is relatively constant regardless of which correction method, was more often used than using the mediastinal vessels [17]. Normalization of the SUVmax using normal liver uptake may minimize the effect of individual bias [18].
The aim of this prospective study was to evaluate the association of primary tumor FDG uptake in form of SUVmax and TLR with clinical, histopathological and molecular characteristics of $\mathrm{BC}$ patients at the initial staging scanning.

\section{Methods}

Forty patients with pathologically proven $\mathrm{BC}$ were recruited in this prospective study. It was approved by local Institutional Committee of Medical Ethics and informed consent was obtained from all participants. Patients were referred for initial staging PET/CT scanning prior to their definite therapy.

Nodal staging was evaluated after axillary clearance or sentinel lymph node biopsies (SLNBs).

We excluded patients who underwent surgery, received chemotherapy or radiotherapy for their breast cancers prior to PET/CT examination, uncontrolled diabetics and pregnant females.

\section{Positron emission tomography/computed tomography protocol.}

Patients fasted for $6 \mathrm{~h}$, and had blood glucose $<180 \mathrm{mg} /$ $\mathrm{dl}$ prior to the study. $0.1 \mathrm{mCi} / \mathrm{kg}$ F18-FDG was injected intravenously in a peripheral vein and scans were acquired at 45-60 min post-injection.

Imaging was performed using high -spatial-resolution, 3 full-ring PET/CT system (Biograph Horizon, Siemens Healthcare).Combining Bismuth Germanium Oxide (BGO) based PET crystal and 16 slice CT components. The patients were allowed to breathe normally. CT and PET scans were acquired from mid-thigh level to the top of the skull with the arms raised.

PET emission counts were collected over $2 \mathrm{~min} /$ table position, acquired in a three-dimensional mode. The imaging data were reconstructed using a point spread function and a time-of-flight algorithm (TrueX + time-of-flight, UltraHD-PET), with 2 iterations and 21 subsets. Subsequently, a Gaussian filter with $5 \mathrm{~mm}$ full-width half-maximum was applied to the reconstructed images. For attenuation and scatter correction, a CT without contrast agent was used. Here, slice thickness was $3 \mathrm{~mm}$ with a pitch of 0.9 and a tube voltage of $120 \mathrm{kV}$. The tube current was automatically modulated according to the patient's size and body shape; a $210 \mathrm{mAs}$ maximum reference value was used to achieve good image quality.

\section{Data Interpretation}

$\mathrm{PET} / \mathrm{CT}$ scans were interpreted by two experienced nuclear medicine physicians blinded to clinical and histopathological data. Gold standard for the evaluation of PET/CT findings was histopathology. The primary tumor was evaluated visually for its site in the breast and 
quantitatively by measuring the lesion SUVmax and TLR as well as the lesion size. The SUV calculation was carried out using the manufacturer's workstation (MI Apps; Siemens). VOI was placed around the lesion, the SUVmax (maximum SUV value within the VOI of each lesion) was recorded automatically on the workstation.

The tumor to liver uptake ratio (TLR) was defined as the ratio of the tumor SUVmax to liver SUVavg. The liver SUVavg was calculated by drawing a circular $3 \mathrm{~cm}$ diameter VOI over the relatively homogenous intense slice of normal liver parenchyma on the PET images.

When a multifocal disease was present, the VOI was placed over the largest visible tumor for calculation of the SUVmax value (Fig. 1).

To determine the metabolic $\mathrm{N}$ stage, any ALNs showing higher uptake than the mediastinal blood pool on PET/ CT images was considered as positive; additionally, we reported quantitative data in form of size and SUVmax.

Any significant abnormal focal increased uptake with suspicious CT features in any part of the body, and not explained by clinically relevant alternative, was considered as positive for distant metastasis.

\section{Statistical analysis:}

Data were verified, coded by the researcher and analyzed using IBM-SPSS 21.0 (IBM-SPSS Inc., Chicago, IL, USA) [19]. Descriptive statistics: Means, standard deviations, medians and inter-quartile range (IQR) were calculated. Test of significances: Independent ttest analysis was carried out to compare the means of dichotomous data that follow normal distribution; otherwise Mann Whitney U and Kruskal-Wallis tests were used to compare the medians, . Spearman ranked correlation coefficient was used to test the associations between scale variables. Variables were entered in multivariable linear regression model to test the independent predictors of SUV of the primary lesion using OR, 95\% CI, p-value. A significant P-value was considered when it is less than 0.05 .

\section{Results}

Patient Characteristics

Forty female patients; 19 (47.5\%) premenopausal and $21(52.5 \%)$ postmenopausal with newly diagnosed BC were enrolled in this prospective study, age ranging
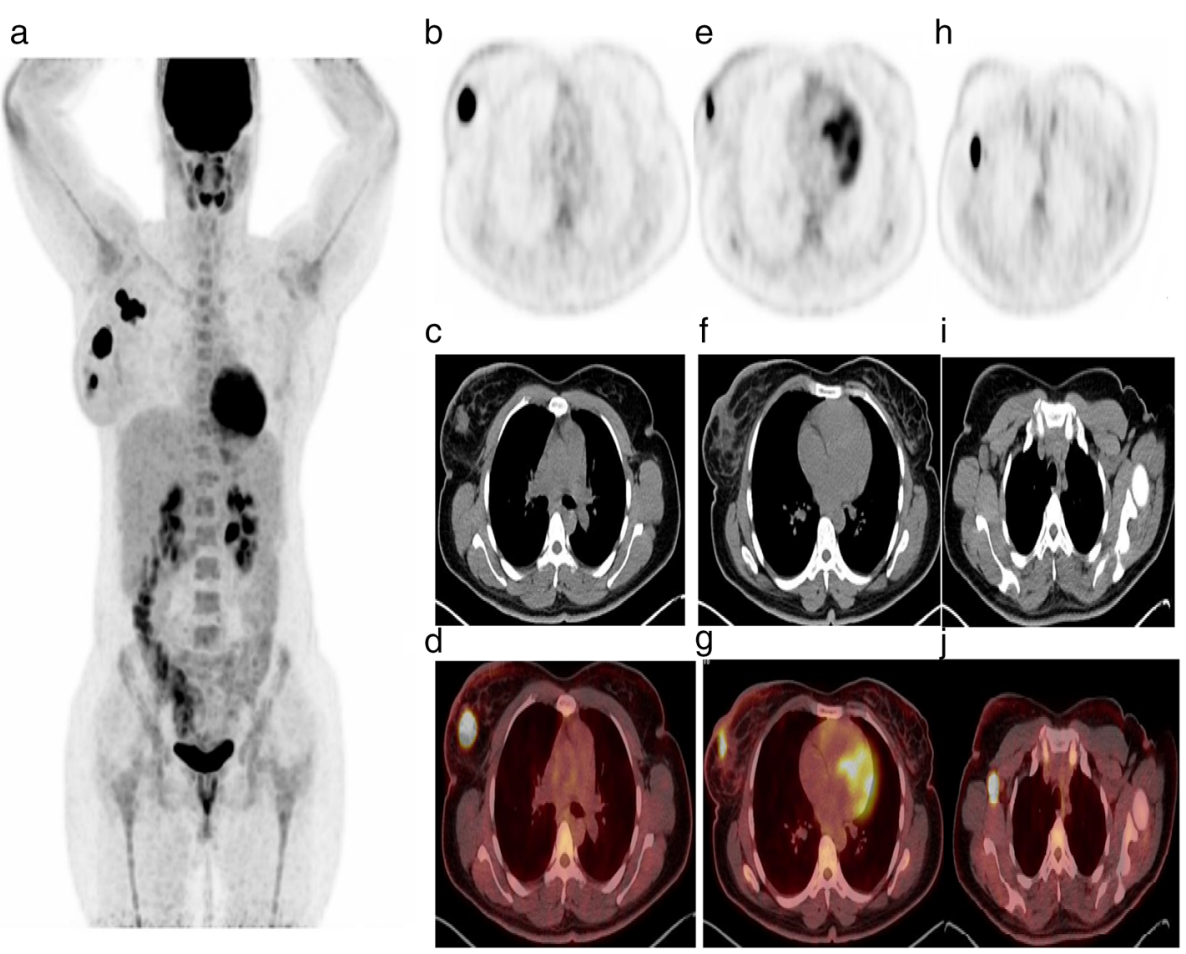

Fig. $1{ }^{18}$ F-FDG PET/CT scan of a 32-years-old female with luminal B Invasive Duct carcinoma GIII of the right breast: a maximum intensity projection, b,c and $\mathbf{d}$ trans axial PET, The corresponding CT and trans axial PET/CT fusion images show intense FDG avid irregular speculated soft tissue mass at the upper outer quadrant of the right breast (the primary lesion) measures about $3.3 \times 2.4 \mathrm{~cm}$ and has SUV max about 20 . e, $\mathbf{f}$ and $\mathbf{g}$ show another FDG avid ill-defined retro areolar satellite lesion inferior to the primary lesion measures about $2.2 \times 1 \mathrm{~cm}$ and has SUV max about 11.2, with mildly FDG avid diffuse thickening of the skin of right breast. $\mathbf{h}, \mathbf{i}$ and $\mathbf{j}$ show intense FDG avid enlarged right axillary lymph nodes. Representative node measures about $2 \times 1.9 \mathrm{~cm}$ and has SUV max about 23.8. TCNB of right axillary lymph nodes revealed positive metastatic axillary LNs 
from 31-78 years (mean 50.5 +/- SD11.7). Twenty-One patients $(52.5 \%)$ had the primary lesion in the right breast while in the remaining 19 cases $(47.5 \%)$ the lesion was in the left one. In half of the patients the primary lesion was present in the upper outer quadrant (UOQ)( 16 of them had positive ALNs uptake), 11 cases in the upper inner quadrant (UIQ) (6 of them had positive ALNs), 4 cases in the central region (all of them showed positive ALNs uptake), 3 cases in the lower outer quadrant(LOQ) (one of them had positive ALNs uptake) and 2cases in the lower inner quadrant(LIQ) with ALNs uptake in both $(\mathrm{P}=0.041)$.

Regarding the clinical staging, more than half of the patients were stage II (21 patients representing 52.5 $\%)$, stage III representing $27.5 \%$, stage I representing $15 \%$, while stage IV representing $5 \%$ of our study population.
Most of the primary tumors; 36 (90\%) were invasive ductal carcinoma (IDC) of no special subtype, 3 cases were invasive lobular carcinoma (ILC) (Fig. 2) and one case of mucinous type. As regard to the receptor status; ER+ were found in $31(77.5 \%)$ and ER- were found in $9(22.5 \%)$ patients, $24(60 \%)$ patients were $\mathrm{PR}+$ while $16(40 \%)$ patients were PR-, Her2neu receptors were positive in 14 patients (35\%) and negative in the remaining 26 (65\%) .Majority of our patients were luminal B (19), while luminal A, TN and HER2 neu overexpression represented in 10, 7 and 4 patients, respectively.

$\mathrm{PET} / \mathrm{CT}$ detected all the primary tumors with mean SUVmax 10.8 (+/-SD 7.9). The mean SUVmax values of the primary tumor were significantly higher in premenopausal, stage III and IV, ER - , GIII, TN molecular subgroup and in patients with positive ALNs $(\mathrm{P}=0.003$,

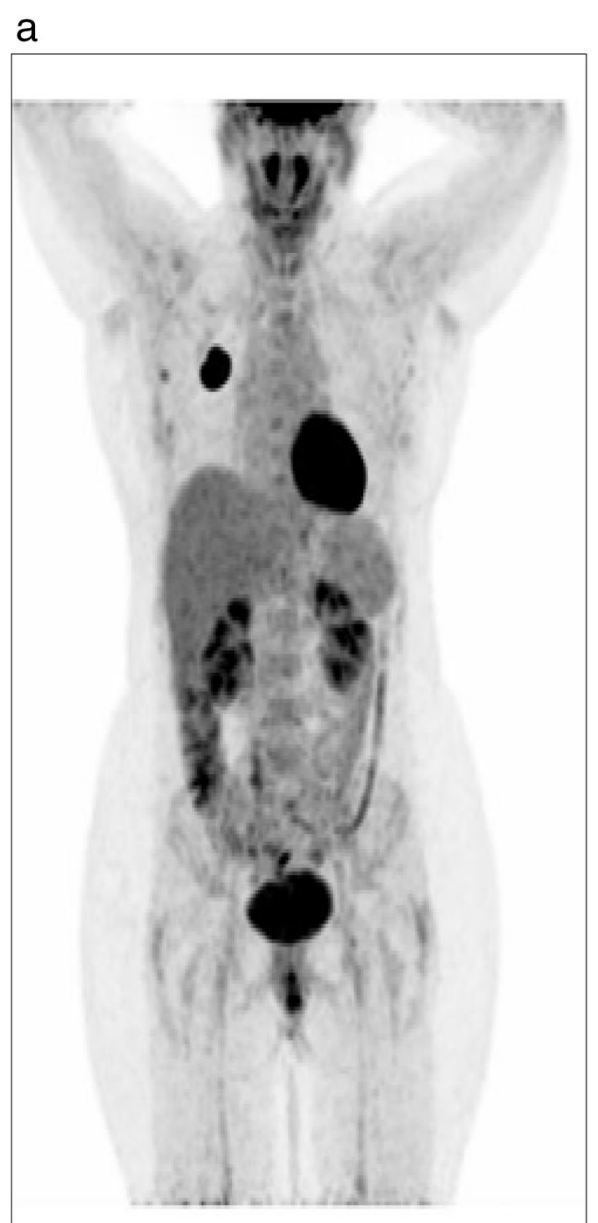

b

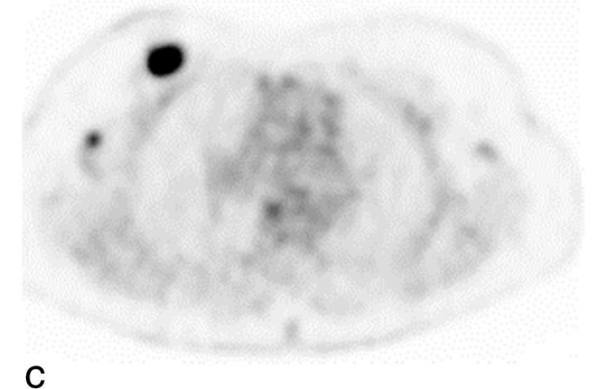

C
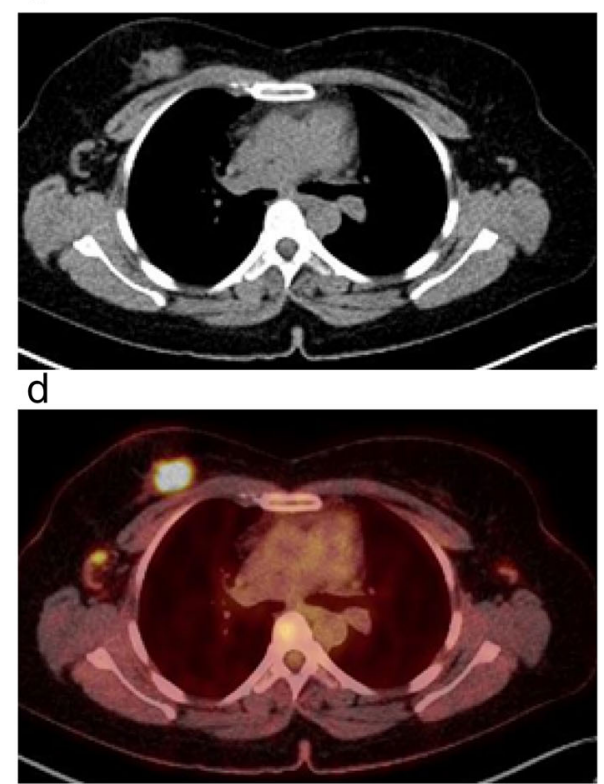

Fig. $2^{18}$ F-FDG PET/CT scan of a 43-years-old female with luminal A Invasive Lobular carcinoma Gll of the right breast: a maximum intensity projection, b trans axial PET show large hypermetabolic intense FDG-avid well-defined right breast lesion, located at its upper inner quadrant. c The corresponding $\mathrm{CT}$ and $\mathbf{d}$ trans axial PET/CT fusion images revealed that 18F-FDG uptake is corresponding to speculate soft tissue density lesion measures about $3.2 \times 2.3 \mathrm{~cm}$ and has SUV max about 17.84. Also, noted enlarged level I right axillary lymph node measures about $2.3 \times 1.5 \mathrm{~cm}$ with SUV max about 3.5 at the thickened part of its cortex. The patient underwent right Lumpectomy \& SLNB revealed positive metastatic axillary LNs 
Table 1 Determinants of the primary Lesion SUVmax among cases

\begin{tabular}{|c|c|c|c|}
\hline & \multicolumn{2}{|c|}{ Lesion SUVmax } & \multirow[t]{2}{*}{ P-value } \\
\hline & Mean \pm SD & Median (IQR) & \\
\hline \multicolumn{4}{|l|}{ Pathology } \\
\hline - IDC(n=36) & $3.96 \pm 3.1$ & $2.85(3.33)$ & $=0.258 \#$ \\
\hline - ILC(n=3) & $2.41 \pm 2.98$ & 0.8 & \\
\hline - Other $(n=1)$ & 1 & & \\
\hline \multicolumn{4}{|l|}{ Menopausal State } \\
\hline - Pre- $(n=19)$ & $14.55 \pm 2.1$ & $13(6)$ & $0.003^{*}$ \\
\hline - Post- $(n=21)$ & $7.45 \pm 1.0$ & $7(2)$ & \\
\hline \multicolumn{4}{|l|}{ Disease Stage } \\
\hline - I \& II (n=27) & $8.79 \pm 1.1$ & $7(2)$ & $=0.017^{*}$ \\
\hline - III \& IV (n=13) & $15.06 \pm 2.9$ & $14(5)$ & \\
\hline \multicolumn{4}{|l|}{ ER-Receptors } \\
\hline Positive $(n=31)$ & $9.12 \pm 5.7$ & $7(6)$ & $=0.010^{* *}$ \\
\hline Negative $(n=9)$ & $16.70 \pm 9.6$ & $12.5(11)$ & \\
\hline \multicolumn{4}{|l|}{ PR-Receptors } \\
\hline Positive $(n=24)$ & $9.13 \pm 6.2$ & $7(5)$ & $=0.113^{* *}$ \\
\hline Negative $(n=16)$ & $13.37 \pm 9.7$ & $9(8.5)$ & \\
\hline \multicolumn{4}{|l|}{ Her2-neu Receptors } \\
\hline Positive $(n=14)$ & $12.35 \pm 5.8$ & $13(9.5)$ & $=0.089 * *$ \\
\hline Negative $(n=26)$ & $10.01 \pm 8.9$ & $7(6.5)$ & \\
\hline \multicolumn{4}{|l|}{ Tumor grad } \\
\hline GI $(n=5)$ & $3.69 \pm 1.4$ & $3.1(2.6)$ & \\
\hline GII $(n=18)$ & $9.43 \pm 6.11$ & $6.85(11.08)$ & $=0.002 \#$ \\
\hline GIII $(n=15)$ & $15.03 \pm 9.20$ & $11.11(13.4)$ & \\
\hline \multicolumn{4}{|l|}{ Molecular subtype } \\
\hline Luminal $A(n=10)$ & $5.88 \pm 4.9$ & $4.18(5.06)$ & $0.007 \#$ \\
\hline Luminal B $(n=19)$ & $10.93 \pm 5.55$ & $8.4(9)$ & \\
\hline Her2neu over expression $(n=4)$ & $8.03 \pm 5.24$ & 7.98(9.13) & \\
\hline Triple negative $(n=7)$ & $19.19 \pm 11.86$ & $21.6(17.67)$ & \\
\hline \multicolumn{4}{|l|}{ Axillary LN State } \\
\hline Positive $(n=27)$ & $12.80 \pm 8.6$ & $10(8.5)$ & $=0.016^{* *}$ \\
\hline Negative $(n=13)$ & $6.73 \pm 4.1$ & $6.5(6)$ & \\
\hline
\end{tabular}

*Independent t-test

**Mann Whitney U

\# Kruskal Wallis test

$0.017,0.01,0.002,0.007$ and 0.016 respectively). But it was insignificantly higher in PR- and Her2 neu + patients $(\mathrm{P}=0.113$ and 0.089$)$ as shown in Table 1 .

In linear regression model, the statistically significant independent predictor factors of the primary lesion SUVmax are; age, advanced stage, postmenopausal, ERand ALNs positive cases, as shown in Table 2 \& Fig. 3.

The mean TLR values were significantly higher in premenopausal, Her2neu +, GIII and TN molecular subtype patients $(\mathrm{P}=0.002,0.0476,0.005$ and 0.018 respectively).The median of TLR values were significantly higher in stage III and IV as well as in patients with positive ALNs $(\mathrm{P}=0.039$ and 0.022 respectively), also it was higher in ER and PR negative patients but with no statistically significant differences $(\mathrm{P}=0.095$ and 0.129 respectively) Table 3.

SUVmax of the primary lesion and TLR were significantly moderately negatively correlated with the age of the patients $(\mathbf{r}=0.405$ and 0.414

respectively with $\mathrm{P}=0.005$ and 0.008 respectively). Also they were significantly moderately positively correlated with the size of the primary lesion $(\mathbf{r}=0.328$ and 
Table 2 Independent Predictors of SUVmax of the primary Lesion: Linear Regression Model

\begin{tabular}{llll}
\hline Variable & $\boldsymbol{\beta}(\mathbf{9 5} \% \mathrm{Cl})$ & T-Statistics & P-value \\
\hline - Constant & $23.50(12.79-34.23)$ & 4.437 & $<0.001$ \\
- Age/years & $-0.25(-0.46:-0.04)$ & -2.455 & $=0.019$ \\
- Disease Stage (III \& IV) & $6.27(1.16-11.37)$ & 2.485 & $=0.017$ \\
- Post-menopausal & $-7.10(-11.71:-2.49)$ & -3.12 & $=0.003$ \\
- ER-Receptors (Negative) & $7.58(1.93-13.23)$ & 2.717 & $=0.010$ \\
- PR-Receptors (Negative) & $4.24(-0.84-9.31)$ & 1.691 & $=0.099$ \\
- Her2 neu -Receptors (Negative) & $-2.35(-7.70-3.00)$ & -0.889 & $=0.379$ \\
- Tumor Size/cm & $2.24(-0.14-4.63)$ & 1.903 & $=0.065$ \\
- Axillary LN (Positive) & $-6.07(-0.93--11.20)$ & 2.393 & $=0.022$ \\
\hline
\end{tabular}

$\mathrm{Cl}$, Confidence Interval

0.337 respectively with $\mathrm{P}=0.019$ and 0.036 respectively) as shown in Table 4.

\section{Nodal staging}

In the Twenty-Three patients who underwent nodal staging (axillary dissection in $7 / 23$ patients and SLNBs in 16/23 patients Fig. 4), 13/23 and 10/23 patients were positive and negative for metastases respectively.

PET/CT was positive in 27 patients with ALNs; out of them 13 proved true positive, 4 were false positive by histopathology and in the remaining 10 cases no pathology report was available. PET/CT negative axillary cases were 13 out of them 6 were true negative by histopathology and in the remaining 7 cases no pathology report were available. The overall sensitivity and specificity of PET/CT for axillary staging was $100 \%$ and $60 \%$, respectively $(\mathrm{P}=0.006)$.

\section{M staging}

PET/CT identified distant metastases in five cases; one skeletal, one hepatic and three cases with mediastinal nodal metastasis.

\section{ROC analysis}

The ROC analysis was performed to examine which parameter (SUVmax or TLR) better reflects the nodal involvement as both parameters were significantly associated with it. Only TLR was poorly predictive of

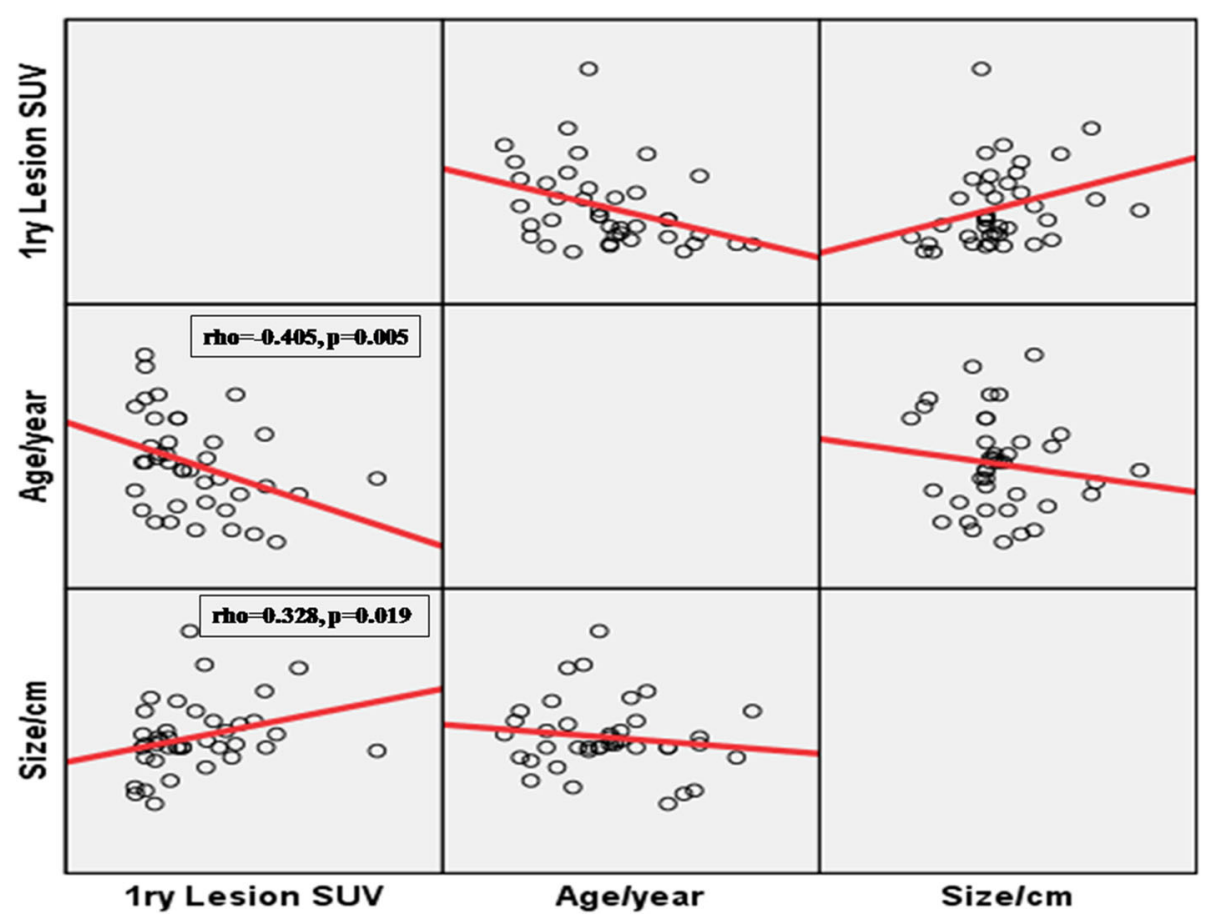

Fig. 3 Linear regression model: Correlation between SUV of the primary lesion, age and tumor Size 
Table 3 Determinants of TLR among cases

\begin{tabular}{|c|c|c|c|}
\hline & \multicolumn{3}{|l|}{ TLR } \\
\hline & Mean \pm SD & Median (IQR) & P-value \\
\hline Pathology: & & & $=0.158 \#$ \\
\hline $\operatorname{IDC}(\mathrm{n}=36)$ & $3.96 \pm 3.10$ & $2.85(3.4)$ & \\
\hline ILC & $2.41 \pm 2.98$ & $0.80(5.3)$ & \\
\hline Others & 1 & & \\
\hline \multicolumn{4}{|l|}{ Menopausal State } \\
\hline Pre- $(n=19)$ & $5.27 \pm 3.55$ & $4.7(5.1)$ & $=0.002^{*}$ \\
\hline Post- $(n=21)$ & $2.41 \pm 1.72$ & $1.88(2)$ & \\
\hline \multicolumn{4}{|l|}{ Disease stage } \\
\hline | \& || (n=27) & $3.21 \pm 2.28$ & $2.32(3.37)$ & $=0.039^{* *}$ \\
\hline III \& IV (n=13) & $4.93 \pm 4.15$ & $2.9(6.36)$ & \\
\hline \multicolumn{4}{|l|}{ ER-Receptors } \\
\hline Positive ( $n=31)$ & $3.12 \pm 2.32$ & $2.5(2.97)$ & $=0.095^{* *}$ \\
\hline Negative $(n=9)$ & $5.99 \pm 4.62$ & $4.7(7.6)$ & \\
\hline \multicolumn{4}{|l|}{ PR-Receptors } \\
\hline Positive $(n=24)$ & $3.12 \pm 2.32$ & $2.56(3.39)$ & $=0.129^{* *}$ \\
\hline Negative $(n=16)$ & $4.74 \pm 3.81$ & $3.25(6.25)$ & \\
\hline \multicolumn{4}{|l|}{ Her2 neu -Receptors } \\
\hline Positive $(n=14)$ & $4.26 \pm 2.46$ & $4(4.23)$ & $=0.0476^{*}$ \\
\hline Negative $(n=26)$ & $3.51 \pm 3.37$ & $2.17(2.68)$ & \\
\hline \multicolumn{4}{|l|}{ Axillary LN Stat } \\
\hline Positive ( $n=27$ ) & $4.58 \pm 3.39$ & $3.52(5.54)$ & $=0.022^{* *}$ \\
\hline Negative $(n=13)$ & $2.10 \pm 1.26$ & $1.86(1.96)$ & \\
\hline \multicolumn{4}{|l|}{$\begin{array}{l}\text { Tumor grade } \\
\text { - GI }(n=5) \\
\text { - GII }(n=18) \\
\text { - GIII }(n=15)\end{array}$} \\
\hline GI $(n=5)$ & $1.35 \pm 0.6$ & $1.16(1.13)$ & $=0.005 \#$ \\
\hline $\mathrm{G} \|(\mathrm{n}=18)$ & $3.21 \pm 2.26$ & $2.38(3.35)$ & \\
\hline GIII $(n=15)$ & $5.42 \pm 3.38$ & $3.31 \pm(6)$ & \\
\hline \multicolumn{4}{|l|}{$\begin{array}{l}\text { Molecular subtype } \\
\text { - Luminal A }(n=10) \\
\text { - Luminal B }(n=19) \\
\text { - Her2neuover expression }(n=4) \\
\text { - Basal Like }(n=7) \\
\text { (triple negative) }\end{array}$} \\
\hline Luminal A $(n=10)$ & $1.96 \pm 1.6$ & $1.45(1.77)$ & $=0.018 \#$ \\
\hline $\begin{array}{l}\text { Luminal B }(n=19) \\
\text { - Luminal A }(n=10) \\
\text { - Luminal B }(n=19) \\
\text { - Her2neuover expression ( } n=4) \\
\text { - Basal Like }(n=7) \\
\text { (triple negative) }\end{array}$ & $3.85 \pm 2.27$ & $3(3.66)$ & \\
\hline Her2neu-overexpression expression $(n=4)$ & $2.57 \pm 1.74$ & $2.26(3.25)$ & \\
\hline Triple negative $(n=7)$ & $6.9 \pm 4.82$ & $8.12(8.29)$ & \\
\hline
\end{tabular}

*Independent t-test

**Mann Whitney U test

\#Kruskal Wallis test 
Table 4 Correlation between metabolic PET parameters, Age and Tumor size

\begin{tabular}{llllll}
\hline Parameter & \multicolumn{2}{l}{ SUVmax } & & \multicolumn{2}{l}{ TLR } \\
\cline { 2 - 3 } \cline { 6 - 6 } \cline { 6 - 6 } & rho* & p-value & & rho* & p-value \\
\hline Age/years & -0.405 & 0.005 & & -0.414 & 0.008 \\
Tumor Size/cm & 0.328 & 0.019 & & 0.337 & 0.036
\end{tabular}

*Spearman's Rank Correlation Coefficient

nodal involvement with AUC of 0.612 (95\% CI: 0.431792) Fig. 5.

\section{Discussion}

$\mathrm{BC}$ is a heterogeneous malignancy owing to several factors affecting its behavior and prognosis [20]. Due to this heterogeneity, the optimal treatment and expected therapy response may vary substantially for each patient [21].PET/CT is a combined imaging of anatomy and function as well. It does not only show the morphological features of the lesion but it may also report its metabolic information, offering new opportunities for breast cancer's diagnosis, staging, re-staging, and treatment response assessment [22].

SUVmax is a semi quantitative value, and it indicates the degree of 18F-FDG uptake. The density of 18F-FDG uptake in the tumor is related to increased proliferative activity in tumor cells [23].

Primary breast tumors with high 18F-FDG uptake have been associated with poor prognosis compared with those with lower uptake [24]. Several studies investigated the correlations between 18F-FDG uptake described by SUVmax, distinct histopathological and a

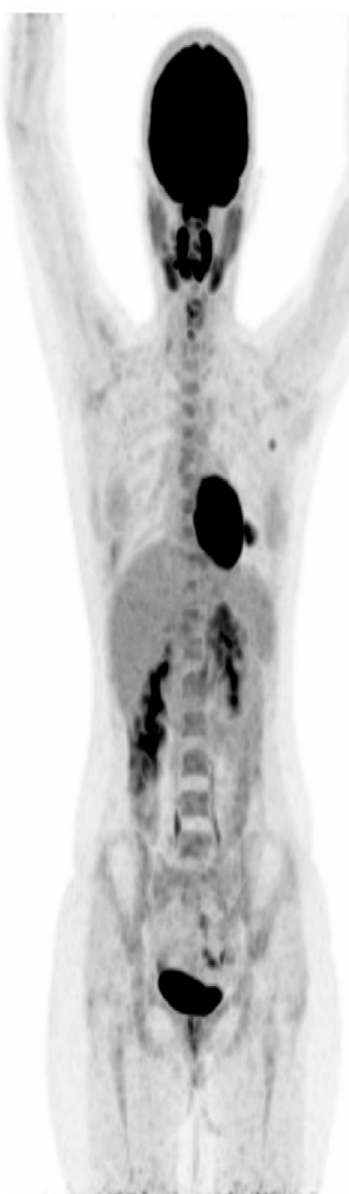

b

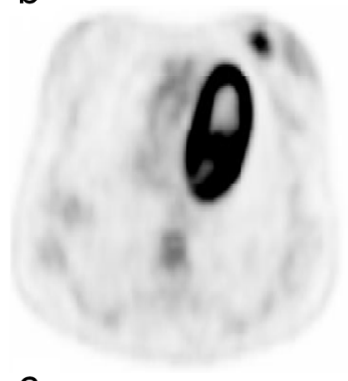

C

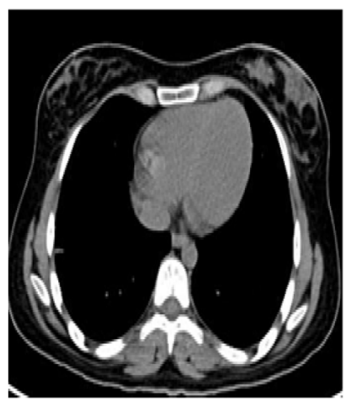

d

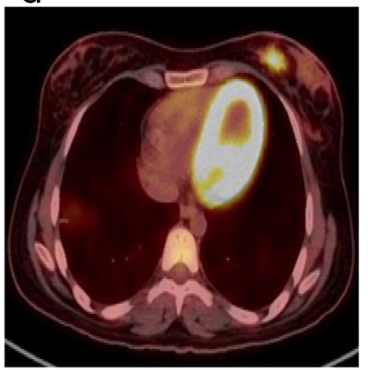

e

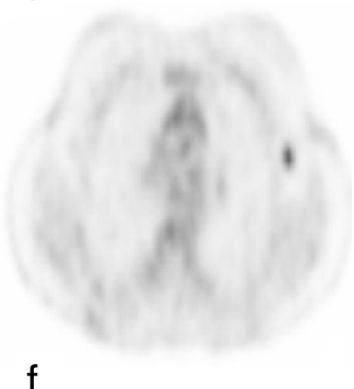

$f$

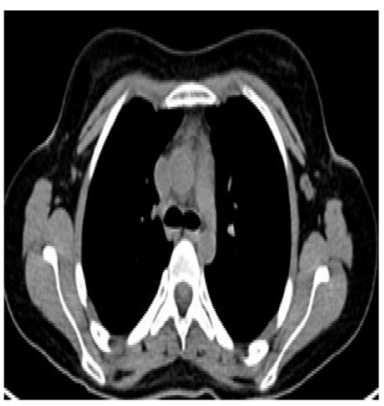

9

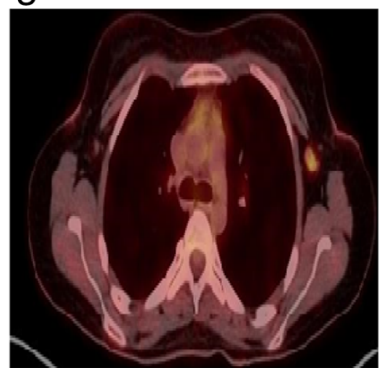

Fig. $4{ }^{18}$ F-FDG PET/CT scan of a 20-years-old female with luminal B Invasive Duct carcinoma Gll of the Left breast: a maximum intensity projection, b, c and $\mathbf{d}$ trans axial PET, The corresponding CT and trans axial PET/CT fusion images show intense FDG avid irregular speculated soft tissue mass at the lower inner quadrant of the Left breast measures about $1.5 \times 1.3 \mathrm{~cm}$ and has SUV max about 6.18. e, $\mathbf{f}$ and $\mathbf{g}$ show small sized FDG avid left axillary level I lymph nodes measuring $0.9 \times 0.9 \mathrm{~cm}$, showing focal cortical thickening reaching $5 \mathrm{~mm}$ with SUV max about 3.2 . SLNB of Left axillary lymph nodes reveal positive metastatic axillary LNs 


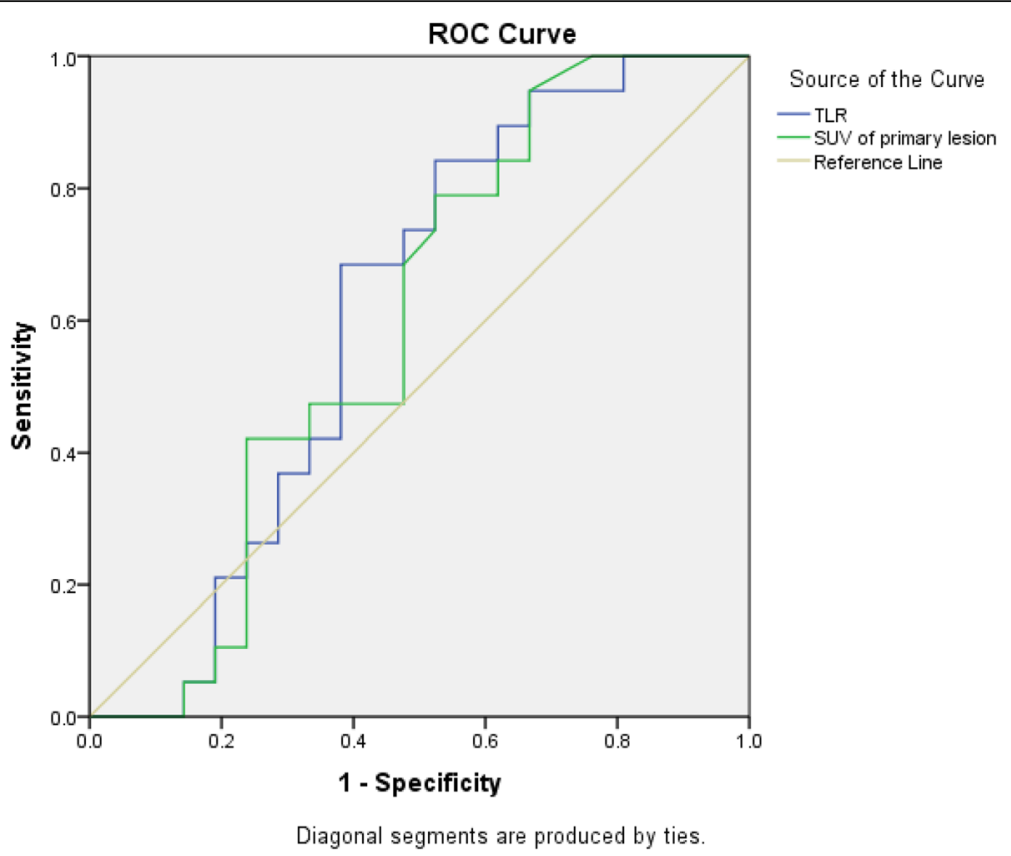

Fig. 5 ROC analysis to determine which PET parameter (SUVmax or TLR) better reflects the nodal involvement

immunhistochemical factors in $\mathrm{BC}[18,24-36]$. In our study ,PET CT detected all the primary tumors with mean SUVmax of 10.8(+/-SD 7.9), in concordance with results of Antunovic et.al [28, 37].Several studies reported a significant lower F-18 FDG uptake in ILC compared with IDC; the authors stated that the lower intensity of tumor cells in lobular carcinomas, lower expression of GLUT1, lower proliferation rates, and diffuse infiltrative tumor growth patterns of the surrounding tissue could explain their results $[25,29,38]$. In agreement with these studies, we found that the median SUV max was lower in ILC compared with IDC ,but with no statistically significancant difference. This is may be explained by smaller numbers of patients included.

The mean SUVmax of the primary tumor was significantly higher in premenopause and advanced stages (stage III and IV); these results are similar to those concluded by Önner et al. and Groheux et al. [18, 29]. The median SUVmax values of the primary tumor in our study was significantly higher in ER - tumors and in PR - ones and these results are similar to those concluded by Ravinaetal [27]..

Kajáry et al. reported that the median SUVmax values of 1ry tumor was significantly higher in Her2neu + patients but in our study the difference was not statistically significant; this is may be attributed to the lower number of cases with Her2neu + (14 versus 58 patients) [33]. TN breast cancer has a more aggressive biology than other subtypes; also it is associated with a poorer outcome than luminal subtypes [39]. Inspite of the few number of $\mathrm{TN}$ cases in the present study the results confirmed significantly higher 18F-FDG uptake in this group than in other molecular subtypes, which comes in line with the results of several studie $s[33,36,40]$.The histological grade of the tumor is a major prognostic factor in BC. Several studies proved that the SUVmax of primary tumor was significantly higher in cases with high nuclear grade tumors similar to ours [32, 33].ALNs metastasis is considered the most important prognostic factor in the $\mathrm{BC}$. Patients with positive ALNs had significantly higher median SUVmax values similar to several studies [35, 41]. Larger tumors contain more tumor cells than the smaller ones, thus requiring a greater glucose supply to maintain the metabolism and proliferation of tumor cells, which would result in an increase in SUVmax. Several studies have demonstrated the association of the maximum tumor size and the tumor SUVmax [42, 43].The SUV max of the primary tumor was positively correlated with the size of the lesion ; this is similar to the results concluded by Abubakar et al. [26]. Additionally, it was negatively correlated with the age of the patients as concluded by Kimet al [44]. ; this is in contrast to several studies that found that there was no statistically significant association between the SUVmax and age [34, 36].

In contrast to our results, Ravinaetal. stated that there was no statistically significant correlation between patient age, tumor size and SUVmax [27].

TLR may provide a better understanding of the metabolic activity of the tumor and a better diagnostic 
performance than SUVmax $[45,46]$. Several recent studies have used TLR as an alternative approach to predicts ALNs metastasis, evaluate the prognosis and treatment response as in assessment prognosis of nodal metastasis in locally advanced $\mathrm{BC}$, predicts poor prognosis in stage IIA colorectal cancer and predict occult lymph node metastasis of non-small cell lung cance $r[18,24,42,46]$.

In our study, we also examined the association of TLR with the aforementioned prognostic factors examined with the SUV max of the primary lesion.

Önner et al. found that the TLR value seems to be more informative than the tumor SUVmax in predicting ALNs involvement and that the median of TLR values was significantly higher in stage III and IV, patients with positive ALNs ,higher tumor grade , ER-, PR-, Her2neu negative and in TN molecular subtype, which were similar to ours [18]. These markers may provide significant information about tumor biology and behavior [18].We found significantly higher TLR values in premenopausal patients. Also, these values were significantly negatively correlated with the age of the patients and significantly positively correlated with the size of the primary tumor. TLR were found to be more predictive of ALNs involvement than SUVmax similar to those concluded by Önner et al. [18].The main Limitations of our study is the small sample size .

\section{Conclusion}

Semi quantitative PET parameters in the form of SUVmax of the primary tumor and TLR values had significant association with different prognostic factors in $\mathrm{BC}$ but only TLR was a poor predictor of nodal metastasis. So these parameters could provide possible relevant information about tumor behavior and biology.

\section{Abbreviations}

FDG-PETCT: Fluorodeoxyglucose positron emission tomography computerized tomography; SUV max: Maximum Standardized Uptake value; TLR: Tumor SUVmax/Liver average SUV Ratio; BC: Breast Cancer; ER+: Estrogen Receptors positive; ER-: Estrogen Receptors negative; PR+: Progesterone Receptors positive; PR-: Progesterone Receptors negative; Her2neu+: Human epidermal growth factor receptor 2 positive; TN: Triple negative; ALNs: Axillary lymph node; AUC: Area under the curve; IHC: Immunohistochemistry; ROI: Region of interest; VOI: Volumetric region of interest; SLNBs: Sentinel lymph node biopsies; BGO: Bismuth Germanium Oxide; IQR: Inter-quartile range; UOQ: Upper outer quadrant; UIQ: Upper inner quadrant; LOQ: Lower outer quadrant; LIQ: Lower inner quadrant; IDC: Invasive ductal carcinoma; ILC: Invasive lobular carcinoma; GLUT1: Glucose transporter 1

\section{Acknowledgements}

Not applicable

\section{Authors' contributions}

Study concepts: MAM, AMZ, MIA. Study design: AAA Data acquisition: AAA. Data analysis and interpretation: AAA. Statistical analysis: AAA. Manuscript preparation: AAA, LME. Manuscript editing: AAA, LME. Manuscript review: AAA, LME, MIA. All authors read and approved the final manuscript.

\section{Funding}

No external funding was obtained for this study.

\section{Availability of data and materials}

The datasets used and analyzed during the current study are available from the corresponding author on reasonable request.

\section{Declarations}

Ethics approval and consent to participate

This study was performed in line with the principles of the Declaration of Helsinki. Approval was granted by the Ethics Committee of faculty of medicine, Assiut University, Egypt, with IRB number17200543. written informed consent had taken from all patients.

\section{Consent for publication}

All patients included in this research gave written informed consent to publish the data contained within this study.

\section{Competing interests}

The authors declare that they have no competing interests.

\section{Author details}

${ }^{1}$ Department of Clinical Oncology and Nuclear Medicine, Faculty of Medicine, Assiut University, Assiut, Egypt. ${ }^{2}$ Nuclear medicine department, National Cancer Institute, Cairo University, Cairo, Egypt.

Received: 4 March 2021 Accepted: 28 June 2021

Published online: 14 July 2021

References

1. Rager O, Lee-Felker SA, Tabouret-Viaud C, Felker ER, Poncet A, Amzalag G, Garibotto V, Zaidi H, Walter MA (2018) Accuracy of whole-body HDP SPECT/ $C T$, FDG PET/CT, and their combination for detecting bone metastases in breast cancer: an intra-personal comparison. American journal of nuclear medicine and molecular imaging 8(3):159-168

2. Chandra P et al (2020) Evaluation of diagnostic accuracy and impact of preoperative positron emission tomography/computed tomography in the management of early operable breast cancers. Indian Journal of Nuclear Medicine: IJNM: The Official Journal of the Society of Nuclear Medicine, India 35(1):40

3. Elsayed AG et al (2018) PET avidity and tumor clinical and pathological features in breast cancer. Proc Am Soc Clin Oncol 36(15_suppl):e12623. https://doi.org/10.1200/JCO.2018.36.15_suppl.e12623

4. Dai $X$ et al (2015) BCintrinsic subtype classification, clinical use and future trends. Am J Cancer Res 5(10):2929

5. Surov A, Meyer HJ, Wienke A (2019) Associations between PET parameters and expression of Ki-67 in breast cancer. Transl Oncol 12(2):375-380. https:// doi.org/10.1016/j.tranon.2018.11.005

6. Jafari SH et al (2018) BCdiagnosis: Imaging techniques and biochemical markers. J Cell Physiol 233(7):5200-5213

7. Segaert I, Mottaghy F, Ceyssens S, de Wever W, Stroobants S, van Ongeval C, van Limbergen E, Wildiers $H$, Paridaens $R$, Vergote I, Christiaens MR, Neven P (2010) Additional value of PET-CT in staging of clinical stage IIB and III breast cancer. Breast J 16(6):617-624. https://doi.org/10.1111/j.1524-4 741.2010.00987.x

8. Yamamoto S et al (2019) Maximum standardized uptake value of 18 Ffluorodeoxyglucose positron emission tomography/computed tomography could replace pathological diagnosis in luminal breast cancer. Annals of Breast Surgery 3. https://doi.org/10.21037/abs.2019.02.01

9. Turkmen C (2019) Nuclear Medicine Imaging in Breast Cancer. In: Breast Cancer Springer, pp 223-237

10. Kitajima K, Miyoshi Y, Yamano T, Odawara S, Higuchi T, Yamakado K (2018) Prognostic value of FDG-PET and DWI in breast cancer. Ann Nucl Med 32(1): 44-53. https://doi.org/10.1007/s12149-017-1217-9

11. Satoh Y, Motosugi U, Omiya Y, Onishi H (2019) Unexpected Abnormal Uptake in the Breasts at Dedicated Breast PET: Incidentally Detected Small Cancers or Nonmalignant Features? Am J Roentgenol 212(2):443-449. https://doi.org/10.2214/AJR.18.20066 
12. Vanderhoek M, Perlman SB, Jeraj R (2012) Impact of the definition of peak standardized uptake value on quantification of treatment response. J Nuc Med 53(1):4-11. https://doi.org/10.2967/jnumed.111.093443

13. Boellaard R, Krak NC, Hoekstra OS, Lammertsma AA (2004) Effects of noise, image resolution, and $\mathrm{ROI}$ definition on the accuracy of standard uptake values: a simulation study. J Nucl Med 45(9):1519-1527

14. Keramida G, Dizdarevic S, Bush J, Peters AM (2015) Quantification of tumour 18 F-FDG uptake: Normalise to blood glucose or scale to liver uptake? Eur Radiol 25(9):2701-2708. https://doi.org/10.1007/s00330-015-3659-6

15. Wahl RL et al (2009) From RECIST to PERCIST: evolving considerations for PET response criteria in solid tumors. Journal of nuclear medicine: official publication, Society of Nuclear Medicine 50(Suppl 1):122S

16. Lee JW, Kim SK, Lee SM, Moon SH, Kim TS (2011) Detection of hepatic metastases using dual-time-point FDG PET/CT scans in patients with colorectal cancer. Mol Imaging Biol 13(3):565-572. https://doi.org/10.1007/s11307-010-0394-x

17. Ali Gholamrezanezhad MD, Muzaffar FR, Osman MM (2012) Respiratory Muscle^ sup 18^ F-FDG Uptake/REPLY. Journal of Nuclear Medicine Technology 40(3):210

18. Önner H, Canaz F, Dinçer M, Işiksoy S, Sivrikoz IAK, Entok E, Erkasap S (2019) Which of the fluorine-18 fluorodeoxyglucose positron emission tomography/computerized tomography parameters are better associated with prognostic factors in breast cancer? Medicine. 98(22):e15925. https:// doi.org/10.1097/MD.0000000000015925

19. IBM_SPSS. Statistical Package for Social Science. Ver.21. Standard version. Copyright (C) SPSS Inc., 2011-2012. NY, USA. 2012

20. Groheux D et al (2013) Performance of FDG PET/CT in the clinical management of breast cancer. Radiology 266(2):388-405

21. Goldhirsch A, Wood WC, Coates AS, Gelber RD, Thürlimann B, Senn HJ, Panel members (2011) Strategies for subtypes - dealing with the diversity of breast cancer: highlights of the St Gallen International Expert Consensus on the 1ry Therapy of Early BC2011. Ann Oncol 22(8):1736-1747. https://doi. org/10.1093/annonc/mdr304

22. Shin S, Pak K, Kim SJ (2016) Tumor heterogeneity assessed by 18F-FDG PET/CT is not significantly associated with nodal metastasis in BCpatients. Oncology research and treatment 39(1-2):61-66. https://doi.org/10.1159/000442760

23. Higashi K, Clavo AC, Wahl RL (1993) Does FDG uptake measure proliferative activity of human cancer cells? In vitro comparison with DNA flow cytometry and tritiated thymidine uptake. J Nucl Med 34(3):414-419

24. Lee SH, Kim SH, Park HS, Kim JH, Kim D, Cho H, Yun M (2019) The prognostic value of $18 \mathrm{f}-\mathrm{fdg}$ uptake in the supraclavicular lymph node (n3c) on Pet/ct in patients with locally advanced BCwith clinical N3c. Clin Nucl Med 44(1):e6-e12. https://doi.org/10.1097/RLU.0000000000002365

25. Ueda S, Tsuda H, Asakawa H, Shigekawa T, Fukatsu K, Kondo N, Yamamoto M, Hama Y, Tamura K, Ishida J, Abe Y, Mochizuki H (2008) Clinicopathological and prognostic relevance of uptake level using 18Ffluorodeoxyglucose positron emission tomography/computed tomography fusion imaging (18F-FDG PET/CT) in 1ry breast cancer. Jpn J Clin Oncol 38(4):250-258. https://doi.org/10.1093/jjco/hyn019

26. Abubakar ZA, Akepati NKR, Bikkina P (2019) Correlation of maximum standardized uptake values in 18F-Fluorodeoxyglucose positron emission tomography-computed tomography scan with immunohistochemistry and other prognostic factors in breast cancer. Indian Journal of Nuclear Medicine: IJNM: The Official Journal of the Society of Nuclear Medicine, India 34(1):10

27. Alavi J (2019) 18 Utility of F-FDG PET/CT in pre-surgical risk stratification of patients with breast cancer. Hellenic journal of nuclear medicine 22(3):165-171

28. Antunovic L, Gallivanone F, Sollini M, Sagona A, Invento A, Manfrinato G, Kirienko M, Tinterri C, Chiti A, Castiglioni I (2017) [18 F] FDG PET/CT features for the molecular characterization of 1ry breast tumors. Eur J Nucl Med Mol Imaging 44(12):1945-1954. https://doi.org/10.1007/s00259-017-3770-9

29. Groheux D, Giacchetti S, Moretti JL, Porcher R, Espié M, Lehmann-Che J, de Roquancourt A, Hamy AS, Cuvier C, Vercellino L, Hindié E (2011) Correlation of high 18 F-FDG uptake to clinical, pathological and biological prognostic factors in breast cancer. Eur J Nucl Med Mol Imaging 38(3):426-435. https:// doi.org/10.1007/s00259-010-1640-9

30. Higuchi T, Nishimukai A, Ozawa H, Fujimoto Y, Yanai A, Miyagawa Y, Murase K, Imamura M, Takatsuka Y, Kitajima K, Fukushima K, Miyoshi Y (2016) Prognostic significance of preoperative 18F-FDG PET/CT for BCsubtypes. Breast 30:5-12. https://doi.org/10.1016/j.breast.2016.08.003

31. Ishiba T, Nakagawa T, Sato T, Nagahara M, Oda G, Sugimoto H, Kasahara M, Hosoya T, Kubota K, Fujioka T, Danenberg P, Danenberg K, Uetake H (2015) Efficiency of fluorodeoxyglucose positron emission tomography/computed tomography to predict prognosis in BCpatients received neoadjuvant chemotherapy. SpringerPlus 4(1):817. https://doi.org/10.1186/s40064-015-1 634-y

32. Kaida H, Toh U, Hayakawa M, Hattori S, Fujii T, Kurata S, Kawahara A, Hirose Y, Kage M, Ishibashi M (2013) The relationship between 18F-FDG metabolic volumetric parameters and clinicopathological factors of breast cancer. Nucl Med Commun 34(6):562-570. https://doi.org/10.1097/MNM.0b013e3283 $60 d 945$

33. Kajáry K, Tőkés T, Dank M, Kulka J, Szakáll S, Lengyel Z (2015) Correlation of the value of 18F-FDG uptake, described by SUVmax, SUVavg, metabolic tumour volume and total lesion glycolysis, to clinicopathological prognostic factors and biological subtypes in breast cancer. Nucl Med Commun 36(1): 28-37. https://doi.org/10.1097/MNM.0000000000000217

34. Koo HR, Park JS, Kang KW, Han W, Park IA, Moon WK (2015) Correlation between 18 F-FDG uptake on PET/CT and prognostic factors in triplenegative breast cancer. Eur Radiol 25(11):3314-3321. https://doi.org/10.1007/ s00330-015-3734-z

35. Tuzcu SA et al (2020) The association of axillary lymph node-positive BC with metabolic parameters of 18F-fluorodeoxyglucose PET/CT. Medical Science and Discovery 7(3):445-449. https://doi.org/10.36472/msd.v7i3.363

36. Yildirim N, Simsek M, Aldemir MN, Bilici M, Tekin SB (2019) Relationship between 18-FDG-PET/CT and Clinicopathological Features and Pathological Responses in Patients with Locally Advanced Breast Cancers. The Eurasian journal of medicine 51(2):154-159. https://doi.org/10.5152/eurasianjmed.201 8.18036

37. Sanli Y, Kuyumcu S, Ozkan ZG, Işık G, Karanlik H, Guzelbey B, Turkmen C, Ozel S, Yavuz E, Mudun A (2012) Increased FDG uptake in BC is associated with prognostic factors. Ann Nucl Med 26(4):345-350. https://doi.org/10.1 007/s12149-012-0579-2

38. Buck A, Schirrmeister H, Kühn T, Shen C, Kalker T, Kotzerke J, Dankerl A, Glatting G, Reske S, Mattfeldt T (2002) FDG uptake in breast cancer: correlation with biological and clinical prognostic parameters. Eur J Nucl Med Mol Imaging 29(10):1317-1323. https://doi.org/10.1007/s00259-002 0880-8

39. Caudle AS et al (2012) Local-regional control according to surrogate markers of BCsubtypes and response to neoadjuvant chemotherapy in BCpatients undergoing breast conserving therapy. BCResearch 14(3):R83

40. Arslan E, Çermik TF, Trabulus FDC, Talu ECK, Başaran \$̧ (2018) Role of 18FFDG PET/CT in evaluating molecular subtypes and clinicopathological features of 1ry breast cancer. Nucl Med Commun 39(7):680-690. https://doi. org/10.1097/MNM.0000000000000856

41. An Y-S, Kang DK, Jung Y, Kim TH (2017) Volume-based metabolic parameter of BCon preoperative 18F-FDG PET/CT could predict axillary lymph node metastasis. Medicine 96(45):e8557. https://doi.org/10.1097/MD. 0000000000008557

42. Huang J, Huang L, Zhou J, Duan Y, Zhang Z, Wang X, Huang P, Tan S, Hu P, Wang J, Huang M (2017) Elevated tumor-to-liver uptake ratio (TLR) from 18 F-FDG-PET/CT predicts poor prognosis in stage IIA colorectal cancer following curative resection. Eur J Nucl Med Mol Imaging 44(12):1958-1968. https://doi.org/10.1007/s00259-017-3779-0

43. Gu J, Yamamoto H, Fukunaga H, Danno K, Takemasa I, Ikeda M, Tatsumi M, Sekimoto M, Hatazawa J, Nishimura T, Monden M (2006) Correlation of GLUT-1 overexpression, tumor size, and depth of invasion with 18F-2-fluoro2-deoxy-D-glucose uptake by positron emission tomography in colorectal cancer. Dig Dis Sci 51(12):2198-2205. https://doi.org/10.1007/s10620-0069428-2

44. Kim J et al (2020) Factors affecting the negative predictive value of positron emission tomography/computed tomography for axillary lymph node staging in BCpatients. Asian Journal of Surgery 43(1):193-200

45. Sarikaya I, Sarikaya A (2019) Assessing PET parameters in oncologic 18F-FDG studies. Journal of Nuclear Medicine Technology 119:236109

46. Shi Y-M, Niu R, Shao XL, Zhang FF, Shao XN, Wang JF, Wang XS, Liu B, Yu WJ, Wang YT (2020) Tumor-to-liver standard uptake ratio using fluorine-18 fluorodeoxyglucose positron emission tomography computed tomography effectively predict occult lymph node metastasis of non-small cell lung cancer patients. Nucl Med Commun 41(5):459-468. https://doi.org/10.1097/ MNM.0000000000001173

\section{Publisher's Note}

Springer Nature remains neutral with regard to jurisdictional claims in published maps and institutional affiliations. 